\title{
Deformation Calculation of HDPE Pipeline under uneven settlement of Landfill Site
}

\author{
Chen Shu ${ }^{1,2, a}$, He Yongxiang ${ }^{3}$, Zhou Taohong ${ }^{3}$,Cai Hualong ${ }^{3}$,Frederick Nai \\ Charkley ${ }^{1,2}$ \\ ${ }^{1}$ Key Laboratory of Ministry of Education for Geomechanics and Embankment Engineering, Hohai \\ University, Nanjing, 210098, China \\ ${ }^{2}$ Geotechnical Research Institute, Hohai University, Nanjing, 210098, China \\ ${ }^{3}$ Construction Management Services Center, Pingshan New District, Shenzhen 518000, China;
}

aemail: 1542363542@qq.com

Keywords: Landfill Site; Pipeline; HDPE; Deformation; Uneven settlement

\begin{abstract}
The capacity expansion project of Yahu landfill site in Pingshan New District of Shenzhen City is based on the old landfill site. It will inevitably cause the inhomogeneity of landfill foundation settlement because of the different new landfill height and the complicated geological conditions, and then cause bending deformation of the permeate discharge guide tube. In this article, the method of layer-wise summation is firstly used to calculate the settlement of pipeline foundation. On the basis of the above settlement calculation, the model of multi-braced steel frame is established to analysis the maximum axial tensile stress and bending degree of pipe by displacement method. The research has a good reference value for judging the safe state of the pipeline under uneven settlement of foundation.
\end{abstract}

\section{Introduction}

With the high-speed economic development and population explosion , Urban size is become more and more big, related city waste is also increased. At present municipal waste mainly adopt the method of land fill for processing[1]. Because early design of the landfill site did not consider the rapid growth of garbage output, capacity of landfill site can't meet the garbage output now, so landfill site need to be renovated. The different height caused by increased garbage filled in the landfill site and complicated geological conditions will inevitably cause the uneven settlement of landfill foundation[2].it will then result in leachate guide tube's bending deformation. Therefore it is particularly important to give the safety evaluation of leachate guide tube of the renovated landfill site. Leachate guide line system is mainly composed of HDPE pipes[3][4][5], the pipe connection mainly adopts the flange connections and welding method, and then decorated on the impervious layer .since the uneven settlement of landfill foundation will cause the deformation of the HDPE pipe, it was needed to verify whether the pipeline's deformation meet the requirements.

\section{Project profile}

The capacity expansion project of Yahu landfill site in Pingshan New District of Shenzhen City is based on the old landfill site. Leachate guide line system is mainly composed of HDPE pipes, respectively, four kinds of pipe which have different diameters had been laid. Specific parameters are shown in Table 1. 
Table 1 Pipe type and parameters

\begin{tabular}{ccccc}
\hline Type & $\begin{array}{c}\text { Nominal outside diameter } \\
\mathrm{D}(\mathrm{mm})\end{array}$ & $\begin{array}{c}\text { Wall thickness } \\
\mathrm{t}(\mathrm{mm})\end{array}$ & $\begin{array}{c}\text { Elastic modulus } \\
\mathrm{E}(\mathrm{MPa})\end{array}$ & $\begin{array}{c}\text { Tensile strength } \\
\mathrm{f}_{\mathrm{t}}(\mathrm{MPa})\end{array}$ \\
\hline DN300 & 300 & 20 & 194 & 21 \\
DN400 & 400 & 25 & 194 & 21 \\
DN500 & 500 & 30 & 194 & 21 \\
DN600 & 600 & 35 & 194 & 21 \\
\hline
\end{tabular}

The top - down soil layer is composed of plain fill, silty clay and strong weathered mudstone. According to field geological survey, the thickness of plain fill layer is $2.4 \mathrm{~m}$, the thickness of silty clay layer is $8.3 \mathrm{~m}$. According to local geological data, the compressive moduli of silty clay is 23.21MPa. Although the relationship between blow counts $\mathrm{N}$ of standard penetration test (SPT) and the compressive moduli Es of cohesive soil has been established in the Handbook of Engineering Geology (Third Edition). But a large number of tests and engineering practice show that the table for the newly deposited soil is not applicable. Through a large number of standard penetration tests, scholars at home and abroad determine the relationship between blow counts $\mathrm{N}$ of standard penetration test (SPT) and the compressive moduli Es of the newly deposited soil, as shown in Figure 1.

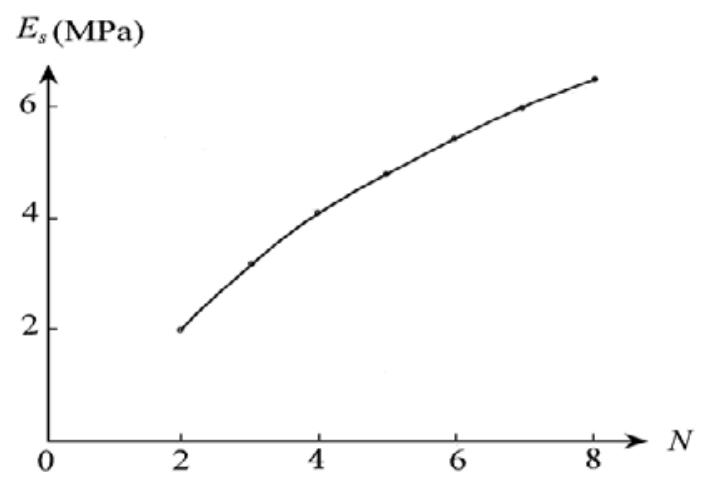

Fig.1 The relationship between blow counts $\mathrm{N}$ and the compressive moduli Es

\section{Settlement calculation method of the landfill foundation}

At present, the calculation methods of foundation settlement can be divided into two categories[6]: one is the engineering practical calculation method represented by the layer-wise summation method; the other is the finite element numerical method which can consider the complex constitutive model. Practical calculation method is still the mainstream of engineering design method because it's simple and convenient. This article uses the method of layer-wise summation to calculate the settlement of landfill foundation. Landfill areas are simplified, as shown in Figure 2.

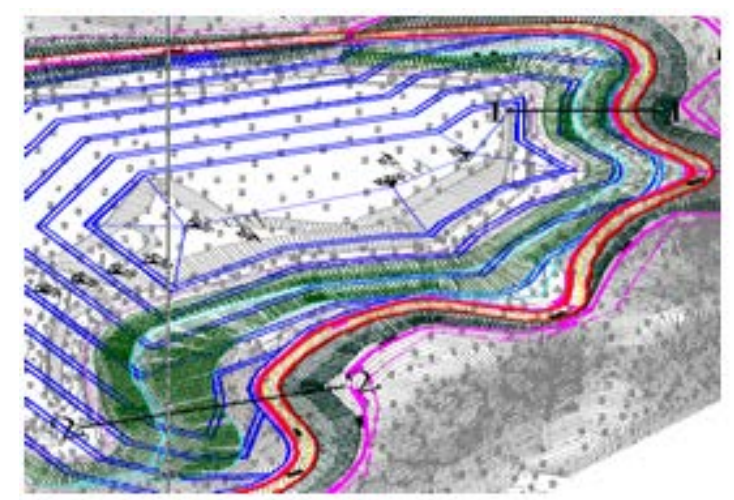

(a) The artwork master of landfill area

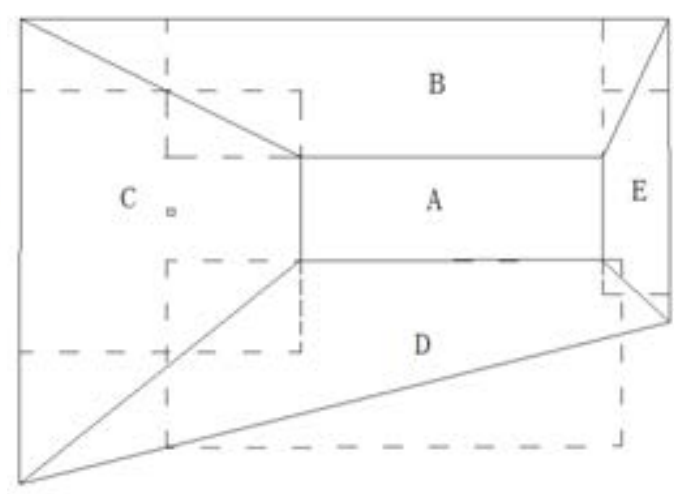

(b) The schematic diagram of landfill area

Fig. 2 The artwork master and schematic diagram of landfill area 
The overburden load of each landfill area is shown in Table 2.

Table 2 The overburden load of each landfill area

\begin{tabular}{ccccc}
\hline $\mathrm{A}$ & $\mathrm{B}$ & $\mathrm{C}$ & $\mathrm{D}$ & $\mathrm{E}$ \\
\hline $\mathrm{Pn}=360 \mathrm{kPa}$ & $\mathrm{Pn}=384 \mathrm{kPa}$ & $\mathrm{Pn}=518.4 \mathrm{kPa}$ & $\mathrm{Pn}=384 \mathrm{kPa}$ & $\mathrm{Pn}=278.4 \mathrm{kPa}$ \\
\hline
\end{tabular}

It is assumed that the foundation soil is a isotropic linearly deformed semi-infinite volume. According to the basic principle of Buchnersk solution and equivalent load method, the load of the landfill is equivalent to rectangular basal uniformly distributed load and rectangular base triangular distributed load.

According to the specification and related documents[7][8]

$\mathrm{S}=\sum \frac{\Delta P_{i} H_{i}}{E_{S i}}$

$\mathrm{S}$-the landfill foundation settlement

$\Delta P_{i}$-the the average additional stress of $i$ strata

$E_{s i}$-the soil compression modulus of $i$ strata

$H_{i}$-the thickness of $i$ strata

\section{Calculation of pipeline Bending Deformation}

Combined with deformation and stress characteristics of the pipeline, the pipe is divided into four parts, one end is fixed, one end is simple supported. By calculating the settlement of five equidistant points at the pipe, it is possible to obtain a general understanding of the bending deformation of the pipe. In this article, the maximum axial tensile stress and curvature of the pipeline can be solved by using the hyperstatic multi-support steel frame model without lateral displacement and displacement method. On the basis of the above analysis, the security situation of landfill foundation under the uneven settlement can be realized. Calculating diagram is shown in figure 3:

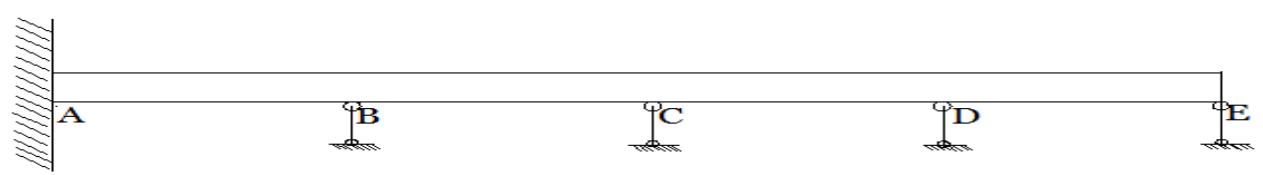

Fig.3 The schematic diagram of calculation model

It is assumed that the stiffness of the HDPE pipes is the same

$\mathrm{i}=\mathrm{EI} / \mathrm{L}$

$i$ - the stiffness of pipe

$\mathrm{L}$ - the length of stepped pipe

The calculation formula of bending moment at points A, B, C, D is as follows

$$
\begin{aligned}
& M_{A B}=2 i \theta_{B}-6 i \frac{\Delta_{B A}}{L} \\
& M_{B A}=4 i \theta_{B}-6 i \frac{\Delta_{B A}}{L} \\
& M_{B C}=4 i \theta_{B}+2 i \theta_{C}-6 i \frac{\Delta_{C B}}{L} \\
& M_{C B}=2 i \theta_{B}+4 i \theta_{C}-6 i \frac{\Delta_{C B}}{L} \\
& M_{C D}=2 i \theta_{C}+4 i \theta_{D}-6 i \frac{\Delta_{D C}}{L} \\
& M_{D C}=2 i \theta_{C}+4 i \theta_{D}-6 i \frac{\Delta_{D C}}{L} \\
& M_{D E}=3 i \theta_{D}-3 i \frac{\Delta_{E D}}{L}
\end{aligned}
$$

$\Delta_{B A}$-the settlement difference between $\mathrm{A}$ and $\mathrm{B}$

$\Delta_{C B}$-the settlement difference between $\mathrm{C}$ and $\mathrm{B}$

$\Delta_{D C}$-the settlement difference between D and C

Through the above formula, bending moment at points can be solved. The calculation formula to solve axial tensile stress of every points in pipe is as follows 
$\sigma=\mathrm{MD} / 2 \mathrm{I}$

$\mathrm{D}$-the outside diameter of the pipe

I -the moment of inertia

Table 3 - Table 6 show the calculation results of all the four different kinds of pipelines.

Table 3 Maximum axial tensile stress of DN300

\begin{tabular}{cccccccc}
\hline tube No. & $\begin{array}{c}\text { depth of } \\
\text { burial }(\mathrm{m})\end{array}$ & $\mathrm{M}_{1}(\mathrm{kN} \cdot \mathrm{m})$ & $\mathrm{M}_{2}(\mathrm{kN} \cdot \mathrm{m})$ & $\mathrm{M}_{3}(\mathrm{kN} \cdot \mathrm{m})$ & $\mathrm{M}_{4}(\mathrm{kN} \cdot \mathrm{m})$ & $\mathrm{M}_{\max }(\mathrm{kN} \cdot \mathrm{m})$ & $\sigma_{\max }(\mathrm{kPa})$ \\
\hline 1 & 1 & -0.6512 & -0.5583 & 0.6595 & 5.0346 & 5.0346 & 3219.686 \\
2 & 2 & 0.5060 & 1.0154 & 1.3656 & 0.2355 & 1.3656 & 1650.035 \\
3 & 3 & 0.8182 & 1.9903 & -2.0077 & 0.7180 & 2.0077 & 760.3758 \\
4 & 4 & -0.0166 & -0.0741 & -0.1860 & -0.2438 & 0.2438 & 662.854 \\
5 & 5 & 0.0453 & 0.0907 & -0.4640 & -1.0633 & 1.0633 & 402.7101 \\
6 & 6 & -0.0354 & -0.0786 & -0.1027 & -0.0853 & 0.1027 & 65.6689 \\
\hline
\end{tabular}

Table 4 Maximum axial tensile stress of DN400

\begin{tabular}{|c|c|c|c|c|c|c|c|}
\hline tube No. & $\begin{array}{l}\text { depth of } \\
\text { burial (m) }\end{array}$ & $\mathrm{M}_{1}(\mathrm{kN} \cdot \mathrm{m})$ & $\mathrm{M}_{2}(\mathrm{kN} \cdot \mathrm{m})$ & $\mathrm{M}_{3}(\mathrm{kN} \cdot \mathrm{m})$ & $\mathrm{M}_{4}(\mathrm{kN} \cdot \mathrm{m})$ & $\mathrm{M}_{\max }(\mathrm{kN} \cdot \mathrm{m})$ & $\sigma_{\max }(\mathrm{kPa})$ \\
\hline 1 & 1 & -0.0919 & -0.0788 & 0.0931 & 0.7104 & 0.7104 & 1931.812 \\
\hline 2 & 2 & 0.4599 & 0.9625 & 0.6369 & -0.4069 & 0.9625 & 1162.904 \\
\hline 3 & 3 & -0.3126 & -0.6281 & -1.8988 & -1.7643 & 1.8988 & 719.1419 \\
\hline 4 & 4 & 0.3954 & 0.9575 & 0.3708 & 0.2599 & 0.9575 & 612.3648 \\
\hline 5 & 5 & 0.0558 & 0.1351 & 0.0523 & 0.0367 & 0.1351 & 367.419 \\
\hline 6 & 6 & -0.0059 & -0.0125 & -0.0153 & -0.0087 & 0.0153 & 41.548 \\
\hline \multicolumn{8}{|c|}{ Table 5 Maximum axial tensile stress of DN500 } \\
\hline tube No. & $\begin{array}{c}\text { depth of } \\
\text { burial (m) }\end{array}$ & $\mathrm{M}_{1}(\mathrm{kN} \cdot \mathrm{m})$ & $\mathrm{M}_{2}(\mathrm{kN} \cdot \mathrm{m})$ & $\mathrm{M}_{3}(\mathrm{kN} \cdot \mathrm{m})$ & $\mathrm{M}_{4}(\mathrm{kN} \cdot \mathrm{m})$ & $\mathrm{M}_{\max }(\mathrm{kN} \cdot \mathrm{m})$ & $\sigma_{\max }(\mathrm{kPa})$ \\
\hline 1 & 1 & 1.0483 & 2.9121 & -0.0375 & 0.3519 & 2.9121 & 1862.337 \\
\hline 2 & 2 & 0.1479 & 0.4109 & -0.0053 & 0.0497 & 0.4109 & 1117.402 \\
\hline 3 & 3 & -0.5634 & -1.2047 & -1.8916 & -1.2597 & 1.8916 & 716.4320 \\
\hline 4 & 4 & -0.2507 & -0.5155 & -1.1002 & -1.3381 & 1.3381 & 506.7918 \\
\hline 5 & 5 & 0.058 & 0.148 & 0.065 & 0.003 & 0.148 & 178.346 \\
\hline 6 & 6 & -0.0050 & -0.0111 & -0.0145 & -0.0120 & 0.0145 & 39.401 \\
\hline
\end{tabular}

Table 6 Maximum axial tensile stress of DN600

\begin{tabular}{ccccccccc}
\hline tube No. & $\begin{array}{c}\text { depth of } \\
\text { burial }(\mathrm{m})\end{array}$ & $\mathrm{M}_{1}(\mathrm{kN} \cdot \mathrm{m})$ & $\mathrm{M}_{2}(\mathrm{kN} \cdot \mathrm{m})$ & $\mathrm{M}_{3}(\mathrm{kN} \cdot \mathrm{m})$ & $\mathrm{M}_{4}(\mathrm{kN} \cdot \mathrm{m})$ & $\mathrm{M}_{\max }(\mathrm{kN} \cdot \mathrm{m})$ & $\sigma_{\max }(\mathrm{kPa})$ \\
\hline 1 & 1 & 0.200 & 0.409 & -0.797 & -1.425 & 1.425 & 1722.120 \\
2 & 2 & -0.1176 & -0.5249 & -1.3185 & -1.7275 & 1.7275 & 1104.757 \\
3 & 3 & 0.8182 & 1.9903 & -2.0077 & 0.7180 & 2.0077 & 760.3758 \\
4 & 4 & 0.0266 & 0.0532 & -0.7166 & -1.0807 & 1.0807 & 409.2840 \\
5 & 5 & -0.0421 & -0.0885 & -0.1083 & -0.0617 & 0.1083 & 69.2460 \\
6 & 6 & 0.007 & 0.014 & 0.026 & 0.020 & 0.026 & 31.584 \\
\hline
\end{tabular}

Table 3 - Table 6 show that 
(1) The bending moment of the guide pipe caused by uneven settlement is generally small, the maximum bending moment occurs at DN500 pipe No.6 is $5.0346 \mathrm{KN} \cdot \mathrm{m}$, the maximum tensile stress is $3.219 \mathrm{MPa}$, less than the pipe limit pull Stress $21 \mathrm{MPa}$, which meet the requirements.

(2) When the uneven settlement of landfill foundation is certain, the greater the guide pipe diameter, the smaller the maximum axial tensile stress.

(3) When the outside diameter of the guide pipe is constant, the deeper the depth of the guide pipe is, the smaller the axial tensile stress is. This is because, with the increase of the buried depth, the additional stress of foundation decreases gradually, the uneven settlement of the foundation becomes weaker .

At the same time, in order to make the guide pipe to meet the requirements of normal use, the relevant specifications also made the requirements to the pipe bending, as shown in Table 7

Table 7 pipe bending limit value

\begin{tabular}{cccc}
\hline the outside diameter of the pipe $d_{\mathrm{e}}(\mathrm{mm})$ & $\leq 32$ & $40 \sim 200$ & $\geq 225$ \\
\hline bending $(\%)$ & no requirement & $\leq 1.0$ & $\leq 0.5$ \\
\hline
\end{tabular}

The pipe bending is calculated as follows:

$\mathrm{R}(\%)=\mathrm{h} / \mathrm{L} \times 100$

$\mathrm{h}$-the maximum height of the chord to curve

I -the length of pipe

The results show that the bending degree of each guide pipe is generally lower than $0.1 \%$, and the maximum curvature is $0.284 \%$ in the pipe No.6, which meet the requirements of the specification. The calculation results are shown in Table 8

Table 8 calculation table of pipe bending

\begin{tabular}{ccccccccc}
\hline tube No. & $\begin{array}{c}\text { depth of } \\
\text { burial (m) }\end{array}$ & endpoint & $\begin{array}{c}\text { at } 1 / 4 \\
\text { pipeline }\end{array}$ & midpoint & $\begin{array}{c}\text { at 3/4 } \\
\text { pipeline }\end{array}$ & & $\begin{array}{c}\text { the length } \\
\text { of pipe } \\
(\mathrm{m})\end{array}$ & $\begin{array}{c}\text { bending } \\
(\%)\end{array}$ \\
\hline 1 & 1 & 0.128 & 0.099 & 0.097 & 0.053 & 0.039 & 27 & 0.050 \\
2 & 2 & 0.128 & 0.183 & 0.186 & 0.193 & 0.209 & 49 & 0.036 \\
3 & 3 & 0.013 & 0.01 & 0.007 & 0.004 & 0.002 & 53 & 0.001 \\
4 & 4 & 0.013 & 0.25 & 0.174 & 0.207 & 0.223 & 46 & 0.122 \\
5 & 5 & 0.017 & 0.013 & 0.007 & 0.004 & 0.002 & 83 & 0.003 \\
6 & 6 & 0.017 & 0.206 & 0.024 & 0.273 & 0.275 & 43 & 0.284 \\
\hline
\end{tabular}

\section{Conclusion}

The capacity expansion project of Yahu landfill site is based on the old landfill site. It will inevitably cause the inhomogeneity of landfill foundation settlement because of the different new landfill height and the complicated geological conditions, and then cause bending deformation of the permeate discharge guide tube. In this article, a model of multi-braced steel frame was established to analysis the maximum axial tensile stress and bending degree of pipe by displacement method. It was verified that the permeable liquid discharge pipe in the landfill capacity expansion project was safe, and the following conclusions were drawn:

(1) The bending moment of the guide pipe caused by uneven settlement is generally small, the maximum bending moment occurs at DN500 pipe No.6 is $5.0346 \mathrm{KN} \cdot \mathrm{m}$, and the maximum tensile stress is $3.219 \mathrm{MPa}$, which is less than the ultimate tensile stress $21 \mathrm{MPa}$, and meet the requirements.

(2) When uneven settlement of landfill foundation is certain, the greater the guide pipe diameter, the smaller the maximum axial tensile stress.

(3) When the outside diameter of the guide pipe is constant, the deeper the depth of the guide pipe is, the smaller the axial tensile stress is. This is because, with the increase of the buried depth, the additional stress of foundation decreases gradually, the uneven settlement of the foundation 
becomes weaker .

\section{Acknowledgement}

The authors appreciate the supports provided by the National Natural Science Foundation of China (No.51578214, 41530637) and Fundamental Research Funds for the Central Universities (No. 2015B17714)

\section{References}

[1] Wang Gang, Bai Yan, Treatment Mode of Domestic Waste in Medium and Small Sized Cities[J], Environmental Sanitation Engineering,2008 16(6) :54- 57.

[2] ZHANG Zhen-ying, CHEN Yun-min, Settlement model of municipal solid waste landfill[J],Journal of Zhejiang University( Engineering Science),2004,38 (9) :1162-1165.

[3] Yang Yiqing, Application of HDPE Geomembrane to Leachate Control of Waste Landfill Site Basement[J], Environmental Sanitation Engineering,2001 9(3) :116-119.

[4] ZHOU Min, DU Yan-jun, WANG Fei, YOU Quan, DONG Dong-dong, Physical modeling of mechanical responses of HDPE pipes and subsurface settlement caused by land subsidence[J],Chinese Journal of Geotechnical Engineering,2016 38(2) :253-262.

[5] CAO Ke, BAI Shu-lin, CHEN Jian-kang, YU Zhong-zhen, Tensile properties of GB /HDPE composites and their influence factors[J], Journal of Aeronautical Materials,1999 19(4) 32-37.

[6] YANG Guanghua, New computation method for soil foundation settlements[J].Chinese Journal of Geotechnical Engineering,2008,04:679-686.

[7] HE Si-ming, Modified layer-summation based on elastopastic theory[J].Rock and Soil Mechanics,2003,01:88-92.

[8]XU Jin-ming1, Tang Yong-jing, Several promotions on layerwise summation method to calculate foundation settlements [J].Rock and Soil Mechanics,2003,04:518-521. 